\title{
Entrevista con el Prof. Dr. Sebastian Scheerer
}

Tamires Maria Alves e Gabriela Laura Gusis

\author{
Sebastian Scheerer \\ Ex-diretor do Instituto de Criminologia da Universidade de \\ Hamburgo e Professor do Departamento de Criminologia na \\ mesma universidade (Hamburgo, Alemanha) \\ E-mail: sebastian.scheerer@wiso.uni-hamburg.de \\ ORCID: https://orcid.org/0000-0002-8622-0463
}

\section{Entrevistadoras (Tamires Alves e Gabriela Gusis):}

Hola Sebastian, ¿Cómo está? Le voy hacer algunas preguntas acerca del seminario que viene realizando en la Universidad de São Paulo y los temas trabajados en este: homicidio, prisiones y drogas. En primer lugar, gracias por haber aceptado participar en esta entrevista. Como estoy realizando una tesis sobre Abolicionismo Penal es un privilegio tenerlo como entrevistado. Sebastian, usted como Nils Christie, Thomas Mathiesen y Löuk Hulsman es considerado uno de los padres del Abolicionismo Penal.

Nuestra revista es sobre Estudios Políticos, así que si puede aclarar un poco a los lectores de lo que se trata el Abolicionismo Penal sería muy importante para nosotros porque cuando las personas escuchan la expresión "abolicionismo penal" suelen quedarse horrorizadas. Las personas creen que es imposible pensar una sociedad sin esta institución penitenciaria, entonces me parece necesario hablar sobre que de hecho es el Abolicionismo Penal.

\section{Sebastian Scheerer:}

Sí, puedo entender esa reacción. Cuando empezamos a hablar sobre abolición de prisiones percibimos que era contraproducente referirse de esta manera. Las personas piensan "vamos, ese hombre es loco", porque cuando ellos piensan que no existirán más prisiones entonces se cuestionan sobre los asesinos, los violadores si estarán todos en las calles y harán lo que quieran y nadie más estará a salvo. Por tanto, de hecho, no parece muy productivo decir que buscamos la abolición de las cárceles. Es en realidad un problema didáctico. Porque la idea inicial es que la sociedad solucione sus problemas sin prisiones, o sea, sin estas tendríamos más seguridad y no menos. Y así podríamos tener más seguridad de un modo mejor y más seguro para lidiar con los crímenes y la delincuencia. Pero esa no parece una concepción muy fácil de pensarse. Eso porque comúnmente las personas suelen igualar prisiones con seguridad. Y lo más importante sería entonces abrir la mente de las personas para las mejores maneras de promover seguridad que las prisiones. Pero eso nos acerca tantos aspectos distintos que me complica para esta entrevista.

Cuando pensamos en excepciones, como las personas que son muy peligrosas para la vida común, como los serial killers. Entonces en prácticamente todos los casos respecto a serial killers necesitamos pensar en confinamiento. Eso significa que necesitamos ponerlos en prisiones y no tendremos como cambiar esta cuestión para las personas muy peligrosas. Ahora sé que eso puede parecer una contradicción para 
la abolición de las prisiones. Pero tengo que ser a favor del confinamiento de los considerados como individuos peligrosos. Pero no soy a favor de confinamiento como un castigo. Porque el confinamiento necesita ser un mecanismo de seguridad apenas en el caso de mantener la sociedad segura de estas personas.

Cuando digo "las prisiones necesitan ser abolidas" lo que eso significa es que la posibilidad de enviar a alguien a la cárcel como castigo por haber cometido un crimen debe ser abolida. Como en Brasil que ya ha eliminado la posibilidad de pena de muerte, la ejecución como castigo. Los jueces en Brasil ya no tienen más la posibilidad legal de decir "yo le sanciono, le iré sentenciar a la pena de muerte", porque ya no existe más la sentencia de muerte en su Código Penal. En algunos otros países todavía existe. Ahora podemos imaginar un país que diga: "La pena de muerte no existe en nuestro Código Penal y las sentencias de prisión tampoco ya no existen más en nuestro Código Penal. Pero hay otras sanciones, como: trabajo social, prisión domiciliaria (aunque todavía se llame prisión no es una prisión efectiva Solo necesita quedarse en casa. Como sucede con algunos famosos involucrados en la Lava Jato. Ellos tienen excelentes casas, con muchos libros, con una infraestructura maravillosa y ellos apenas se quedan en casa).

Entonces lo que realmente tenemos son unas pocas personas en instituciones que se puede llamar de prisiones o no, pero que no son utilizadas exactamente para castigar estas personas, pero si para garantizar la seguridad de la sociedad, y es sobre eso que debemos pensar. No las voy a llamar de prisiones porque no están para castigar estas personas. Son como instituciones psiquiátricas, nosotros no llamamos instituciones psiquiátricas de prisiones porque no han sido creadas para punir a las personas, pero sí para mantener estas personas en seguridad y también mantener la sociedad segura. $Y$ eso es una cuestión muy compleja porque tiene una alta carga política. Y todos los grupos políticos interesados van a decir: "Mira, esta es una persona peligrosa, entonces ella tiene que quedarse en esta institución".

Mira, les digo que el $95 \%$ o más de los que están en las prisiones hoy no deberían tener que seguir en confinamiento por cuestión de seguridad. Entonces no se habría que tener estas más de 600.000 o 700.000 personas confinadas en Brasil, pero capaz 30.000 personas en instituciones que no se parecieran con cárceles, y que no serían instituciones que promulguen el castigo. Estos lugares se parecerían con departamentos o pequeñas casas, bungalós. Y las personas se quedarían en estos lugares porque les diría la sociedad: "Usted necesita sacrificar su libertad porque nosotros no sabemos qué hacer con su peligrosidad". Y eso ya sería algo bastante complejo de hacerse, pero no prenderíamos centenas de miles de personas. Tal vez algunas centenas o hasta mismo, lamentablemente, algunos miles. Lo dudo que llegaría y ese número, quizá a 10.000 personas, pero no lo sé. Porque todo eso depende de la definición de peligrosidad. Solo no permitiríamos más que el castigo de personas sea realizado por la privación de la libertad de estas, como, por ejemplo, hay algunos crímenes no violentos que si quisiéramos seguir castigando deberíamos hacerlo con sentencias alternativas.

Yo particularmente no suelo pensar que debemos castigar a las personas que cometen crímenes violentos. Únicamente debemos- y ahora eso se convierte bastante abstracto

- Únicamente debemos restaurar la validad de la norma que ha sido rota. Debemos hacerlo públicamente y efectivamente debemos exigir al sujeto que asuma sus responsabilidades. Este debe ser responsabilizado y debemos intentar restaurar el daño que ha sido causado a la víctima, a los alrededores de la víctima, a la comunidad. $Y$ aquí se hace complejo porque es necesaria la participación de la comunidad, pero de 
este modo será mucho más civilizado y tendrán mayores aspectos de restauración que apenas el castigo.

El castigo es una manera autoritaria de lidiar con el comportamiento problemático. Eso adviene de la época en que las normas venían del Estado Absolutista. Las leyes del Estado Absolutista estaban para mostrar quién tenía el poder y que el rey podría aplastar a cualquiera que estuviese en su camino. Así esta no era una forma democrática de lidiar con el comportamiento infractor o mismo con el comportamiento peligroso.

Por eso esta tendencia actual de justicia restaurativa tiene mucha de mi simpatía. Yo sé que se puede entender distintas cosas de esta expresión "justicia restaurativa", pero lo que yo entiendo de eso es que el sistema de justicia criminal nos cuestiona ya que la ley ha sido rota quienes hayan hecho eso deben recibir un determinado castigo (dolor) para que sea infligido a esta persona. ¿Entonces la cuenta es de cuantos años se envía esta persona a la cárcel? Y es solo eso.

Por lo tanto, la Justicia Restaurativa tiene una visión completamente distinta de abordaje. La primera pregunta es: ¿Qué daño ha sido causado? Tanto para la víctima, cuanto para las demás personas que sufrieron daños. Varias veces hay muchas víctimas, porque muchas personas son afectadas por un único acto. Entonces es muy importante visualizar quien, y que ha sido afectado y de qué manera, material, emocional, social. Solo después de que encontremos lo que ha sucedido y que tipo de daño se ha causado, entonces podremos pensar que podemos hacer y que se debe hacer para tornar este daño restaurado. Para restablecer esta situación de la mejor manera posible. O hasta mismo podremos pensar en tornar la situación incluso mejor que antes. Porque la situación anterior muchas veces tiene una conexión con una ocurrencia tardía, entonces capaz esa situación anterior pueda ser perfectamente mejorada para que crímenes como los que sucedieron no vuelvan a pasar luego de esa situación. Eso es lo que Ruth Morris llama de Justicia de Transformación, no debemos solamente intentar restaurar, algunas veces puede no servir restaurar algo que no está bueno y que sea injusto. Entonces as veces no es el caso restaurar, pero transformar la situación anterior y cambiarla.

Y apenas a partir de eso surge una tercera pregunta que es: Bueno, alguien provocó este sufrimiento, ¿Quién es esa persona? ¿Por qué lo hizo? ¿Cómo lo hizo? Vamos a escuchar a la persona que parece tener responsabilidad por el hecho. Pero no se lo debe hacer de manera que sometan y subordinen esta persona de manera ofensiva. Es necesario intentar que esta persona se sienta sin miedos, pudiendo tener personas que estima a su lado, para que pueda hablar de manera equitativa con los demás, y no como alguien inferior a los otros. Así, podrá hablar libremente y nosotros podremos entender mejor cuales han sido sus motivaciones en aquella situación. Y de esa forma llegará el día en que miraremos para los hechos narrados y pensaremos "Bueno, ¿De qué manera esa persona puede restaurar o transformar la situación anterior?" Esa persona no será dejada sola para hacerlo, hasta porque nadie solo puede deshacer el sufrimiento que ha causado a otra persona. Es mucho más fácil generar sufrimiento que deshacerse de ello. Con eso esa transformación de la situación va a demandar más gente y más esfuerzos.

De este modo se ve que el «criminoso» no es la persona central y que infligir sufrimiento para punir no es ni siquiera la cuestión. Por otro lado, es muy importante mirar que tipo de actitud el dicho «criminoso» puede tener con la víctima, con las demás personas de la sociedad. Todo ese proceso puede ser un proceso de concienciación sobre el sufrimiento y lo que este sufrimiento ha causado y que 
responsabilidades tiene sobre eso. Entonces esta persona tiene que ser responsable, pero también agregada e integrada, como John Braithwaite decía, se puede reintegrarlo a través de la vergüenza (reintegrated shaming). Eso no siempre es la mejor cosa a hacerse, pero para que se tenga una idea, la reintegración a través de la vergüenza puede hacer la persona pensar: «Hice una cosa mala y lo reconozco, tengo algunas razones buenas y otras malas por haberlo hecho. Creo que no quiero hacer una cosa de esta otra vez, y estoy agradecido de que las personas me ayuden, me auxilien a construir soporte emocional para enfrentar ese momento». $Y$ como investigador me sorprende el número de casos en que hay beneficios emocionales establecidos en el proceso de charlar sobre lo que ha sucedido, que tipo de sufrimiento se ha causado. $Y$ esto es completamente distinto de lo que ocurre en la justicia común.

En la justicia común todo lo que sucede es realizado de arriba para abajo. El habla viene desde arriba, la sentencia es hecha desde arriba, la persona que ha cometido el incidente es desvalorada y puesta afuera de la sociedad adentro de una prisión, y en la prisión en general se convierte en alguien mucho peor de lo que era. Cuanto más tiempo encarcelado peor se quedará. Cuando la persona salir de la prisión saldrá odiando a la prisión, odiando a los guardias penitenciarios, odiando a la sociedad, odiando a la policía, odiando todo el mundo, incluso a sí mismo. La estimativa es que vuelva a hacer algo terrible. Y nosotros lo sabemos, los criminólogos lo saben, entonces esta es la cosa más estúpida a hacerse con la persona para apenas excluirla, rechazarla, desvalorizarla, desposeerla (porque es común salir de la cárcel endeudado) y nadie se importa con eso. Nadie quiere tener una relación con esta persona después de haber salido de la cárcel, excepto otros criminosos. Por lo tanto, es una idea estúpida poner en práctica este sistema penal que tenemos.

Y creemos que vivimos en una sociedad iluminada, iNosotros vivimos en una sociedad medieval! iNo es distinto del Medioevo! En muchos países criminalizan personas porque son gay, eso es completamente medieval. En muchos países personas van presas porque trafican drogas. Quien trafica drogas no hace exactamente nada malo. El consumo de drogas pude tener consecuencias negativas, pero no tiene nada que ver con la ley penal, es semejante a la cuestión del alcohol. Si se prenden a todos los que producen alcohol en las cárceles solamente porque algunas personas matan otras después de consumir alcohol, eso es completamente insano. Eso no tiene nada que ver con la dogmática legal y protección de bienes o de personas. Eso es absurdo, es medieval y sus consecuencias son catastróficas porque destruyen grande parte de la sociedad y destruye la policía por corrupción, destruye el judiciario porque no saben más que están haciendo y los hacen hipócritas. Crea estructuras en la sociedad donde la soledad es normal; donde la corrupción es normal; y eso va directamente para la identidad de la sociedad.

Entonces estamos viviendo un sistema de justicia criminal que no está progresando, sino caminando hacia atrás. Todas las legislaciones de los últimos años son estúpidas e insensibles. Y eso también nos muestra como la sociedad está desmoronando, con personas blancas quienes no les importan las personas negras, ricos quienes no les importan los pobres. Y es así que la sociedad pierde su orientación. Eso no es apenas malo para personas negras o para los pobres, es malo para toda la sociedad. Por tanto, la justicia criminal necesita repensar toda su actuación y eso es la cosa más importante que podemos hacer.

\section{Entrevistadoras:}

Muchas gracias por esa respuesta tan aclaradora para nuestra pregunta. Estuvo muy bueno poder escuchar y entender que el abolicionismo no es sobre «por más asesinos 
en las calles» y si sobre reflexiones sinceras que debemos hacer, principalmente, respecto a las personas marginadas. Hasta para que pensemos sobre los que cometen delitos, incluso a los que involucran situaciones de violencia, aunque haya cometido un asesinato, es necesario que la sociedad te mire y piense si hay tratamiento a realizarse y no apenas que la solución sea tirarlo a una institución que te convertirá en alguien peor.

\section{Sebastian Scheerer:}

Sí, exactamente eso. Y eso va a convergir para una extensión de lo que hacen los evangélicos. Porque por un lado ellos piensan parecido con nosotros, pero por otro lado no defienden lo que defendemos porque piensan distinto en relación a las drogas, por ejemplo. Pero en términos de cuidar a las personas, en tomarlos de verdad como personas que no están definidas completamente por sus acciones, eso es algo que los evangélicos tienen que está muy bueno. ¿Usted conoce a las APACs? Así lo creen dentro de las unidades que manejan. Entonces hay algunas cosas buenas que se pueden charlar con ellos de manera abierta..., igual es difícil.

\section{Entrevistadoras:}

Sí, en Brasil cuando empiezas a hablar y explicar de lo que se trata el Abolicionismo Penal muchas personas dicen, «Ok, pero eso es religión» ...

\section{Sebastian Scheerer:}

Risas. iSí, sí! Pero hay algunos pequeños aspectos en que realmente parecen encontrarse.

\section{Entrevistadoras:}

Sí, porque cuando se habla sobre perdonar al otro, sobre mirar más allá de la acción, eso se parece un poco a un dogma religioso, risas.

Bueno, en este último libro que ha escrito «Manifiesto para Abolir a las Prisiones», Ricardo Genelhú y usted discurren sobre aspectos que han sido trabajados por otros autores como John Braithwaite y hasta mismo lo que discurre la ICOPA - International Conference of Penal Abolitionism fundada por Louk Hulsman. En el libro hablan sobre otras posibilidades de trabajarse con una sociedad sin prisiones. ¿Usted cree que estas alternativas posibles como los hospitales psiquiátricos que permanecen con el paciente en análisis, viendo cuales han sido sus avances y si ha progresado y podría cambiar para un régimen de semilibertad etc., eso sería posible de suceder con personas que han cometido tipos de «delitos» considerados violentos?

\section{Sebastian Scheerer:}

Bueno, para empezar, creo que no todo asesino es peligroso. El hecho aislado de que alguien haya matado a otra persona no significa que esta persona tendrá que quedarse confinada. Obvio que puede ser que sí, que tenga que quedarse confinada.

En el momento en que alguien mata a otra persona es necesario que esta sea puesta en confinamiento, como una prisión provisoria, porque no sabemos para donde esta persona puede ir y no podemos dejar que desaparezca. Hasta porque no se sabe si esa persona no huirá para otro lugar y en este nuevo lugar podría matar a otra persona. Para eso es necesario que haya la prisión preventiva. Pero esta prisión preventiva es para garantizar que ocurra el proceso, luego el objetivo no es el castigo. Por lo tanto, la prisión preventiva debe ser realizada en un muy buen ambiente, porque no ha sido juzgado, no es culpado y no está allí para ser castigado, solo para que la justicia garantice que estará allí mientras analizan la situación. Entonces es un confinamiento 
profesional que no necesita que sea hecho en una prisión, no es punitivo, pero tiene que ser seguro.

Lo que el abolicionismo tiene la intención de hacer acabar es la prisión como castigo, la prisión como sufrimiento. Si tenemos que punir a las personas, podemos hacerlo de manera distinta a la muerte y también a la prisión. Podemos tener creatividad para lidiar con nuestros problemas. Usted lo sabe, vivimos en un tiempo en que tenemos tantas posibilidades de vigilancia que no necesitamos poner personas en celdas para estar seguros de que tenemos el control sobre ellas. $Y$ ese es un argumento sociológico para el abolicionismo. Actualmente podemos analizar la situación social, podemos encontrar formas de ayudar a la persona al mismo tiempo que la controlamos y hacemos esta persona responsable por lo que ha hecho, o sin que sea necesario punir con la prisión. Y es un pensamiento del siglo XIX el del encarcelamiento, aunque vivamos en el siglo XXI sigue estando en boga...

Desde entonces sucedieran algunas cosas, como estos dispositivos electrónicos que existen hoy, las tobilleras, o miles de tipos de cámaras distintas y también hay personal, trabajadores que son asistentes sociales. Si usamos el dinero destinado para las prisiones para asistentes sociales que realmente se van a importar y cuidar a las personas para controlarlas y para mantener a los que llaman de «criminosos» en vigilancia, entonces, con estos cambios, podremos hacer muchas cosas.

Hasta en Estados Unidos hay programas muy interesantes sobre eso. Uno de ellos llamado reinversión de la justicia criminal (criminal justice reinvestment). En este, el gobierno federal envía dinero para los estados y condados que lo invierten en sentencias no penitenciarias para personas que normalmente irían a las prisiones. $Y$ recompensan a los que son capaces de crear alternativas. ¿Y cómo hacen eso? Ellos envían el dinero que sería invertido en las prisiones y no se está gastando - porque si se enviaría 1000 personas para la cárcel y no se está haciendo, luego se está economizando ese dinero que sería destinado a la prisión de estos 1000, entonces, es bastante dinero. $Y$ ese dinero es enviado al estado y a la comunidad para invertir en habitaciones y livings para estos dichos «criminosos». Con eso, los livings de ellos son limpios, la infraestructura es mejorada etc. Eso se llama criminal justice reinvestment. En algunos Estados como Virginia, lo están haciendo y parece una alternativa interesante.

Y necesitamos ser todavía más inventivos. Cuando habla sobre uno no me gustaría mencionar justamente este caso cliché del taxista, pero es la realidad, ayer yo estaba hablando con un taxista y cuando le pregunté que deberíamos hacer en contra de los criminosos, rápidamente me contestó: «iPonerlos en la cárcel por más tiempo! iHabría que poner más gente en las prisiones, por más tiempo!» algunas veces dicen: «iQue se mueran en la cárcel! iMaten a esos criminosos!». Por cierto, podemos hacer eso, pero ahí tendremos una sociedad distinta, todavía más bárbara. Y se te gusta una sociedad bárbara, todo bien. Pero hay muchas personas que quieren vivir en una sociedad más civilizada.

Y el proceso de civilización tiene muchas cosas por hacer como: la manera que se tratan a los pobres; como se tratan a las minorías; y hasta como se tratan a los «criminosos». Así que, si queremos una sociedad mejor, más feliz que hoy en día y también menos agresiva, debemos inventar métodos que sean más fabulosos e inspiradores que los que matan personas y las dejan presas eternamente dentro de las prisiones, donde serán muertas. Es una cuestión de prioridades.

Mi prioridad es que quiero vivir en una sociedad más feliz donde la gente es digna, 
civilizada, en la cual no nos matamos, donde los más poderosos no matan a los menos poderosos y viceversa. Y parece excelente tener a ese tipo de sociedad. Y para que tengamos eso es necesario que intentemos empezar a tener buenas ideas de lo que puede ser muy bueno para todos. $Y$ lo que es excelente para todos seguramente nos va a llevar para lejos de este tipo de pensamiento horrible que llamamos de prisiones. iEs bastante lógico!

Pero hay tanta frustración en la sociedad y cuanto más desiguales las sociedades, las que tuvieron largos períodos de esclavitud, como ustedes en Brasil, las prisiones son peores que en otras. Es terrible decírselo, pero probablemente es verdad. Ellos tienen esta cuestión histórica muy fuerte. Entiendo de eso porque Alemania es una sociedad que ha sido nazi y tenemos que intentar lidiar con eso también y es muy difícil hacerlo. iPero tenemos que intentar lidiar con esto todo el tiempo!

\section{Entrevistadoras:}

Sí, claro. Me quedo pensando que debe ser muy difícil para usted hablar sobre el abolicionismo y discutir ideas, porque cuando había empezado a escribir sobre este tema la sociedad estaba muy distinta, decayendo el número de prisiones, parecía un escenario prospero para hablar sobre eso. $Y$ ahora nos encontramos en el extremo opuesto... Yendo hacía cada vez más prisiones.

\section{Sebastian Scheerer:}

iSí! Risas... iSí! Todo estaba caminando por otra dirección. Y tiene razón, estamos prendiendo cada vez más personas. Sin embargo, creo que esto está llegando a un punto tan absurdo que cada vez más personas se cuestionan sobre la locura que está pasando. Algunas personas están empezando a preguntarse: «Mira, ¿Capaz no deberíamos volver atrás?» Obvio que hay personas que también dicen: «iNecesitamos crear más prisiones! Solo eso nos traerá más progreso». Eso es terrible y nunca ha funcionado...

Pero, por otro lado, hay gente que está pensando que es necesario delimitar números para que la situación vuelva razonablemente a la normalidad. Pero mismo esta delimitación ha sido la circunstancia que ya nos trajo hasta este hiper-encarcelamiento de la actualidad. Entonces, no debemos restaurar el escenario para cuando teníamos 300 mil presos o 400 mil presos iNecesitamos transformar la situación! Es otra razón por la cual la justicia transformativa tiene sentido. Cuando algo así sale de control como la justicia criminal y el sistema carcelario, apenas se puede decir: «Es verdad, eso ha salido de control. Vamos a intentar controlarlo nuevamente». iEso es una señal de que los tiempos de la cárcel se ha expirado! Así como los tiempos de la pena de muerte se ha expirado, y los tiempos de los gladiadores se ha expirado, los tiempos de Troya se ha expirado... Entonces, ahora se expira los tiempos de las cárceles y nosotros necesitamos entender que estamos en un nuevo momento y que tenemos todas las posibilidades para inventar nuevas posibilidades.

Y será triste si nosotros abolicionistas nos convertimos en apenas unos pocos hablando sobre la necesidad del fin de las cárceles. Tal vez podamos mirar para este escenario de crisis de la cárcel como una oportunidad para la sociedad comprender que apenas poner personas en las cárceles y en celdas minúsculas y superpobladas ya pasó, no funciona más y nunca ha funcionado, y hoy tenemos miles de nuevas posibilidades para lidiar con los conflictos.

\section{Entrevistadoras:}

Sabastian es increíble que piense y milite de esta manera. Me parece una visión 
optimista de la crisis que estamos enfrentando.

Nosotros en Latinoamerica y Brasil estamos cada vez más con planes de agrandar todavía más los complejos penitenciarios. Como lo debe saber, hoy tenemos 726 mil presos en Brasil. La guerra contra las drogas es responsable por mantener encarcelado la mayor parte de estos penalizados. Sabemos que ellos son los chivos expiatorios, 0 sea, jóvenes negros, pobres, con nivel de enseñanza inferior y sin empleos o vivienda fija. Los investigadores discuten que la cuestión de las drogas habría que ser tratada como política pública de salud y no a través de la justicia criminal. Sin embargo, muchas veces la postura de los ciudadanos comunes es creer que los que defienden que las drogas se podrían utilizar o que el consumo y venta no deberían llevar a las personas a las cárceles, son acusados de apologistas o usuarios. Eso porque creen que quienes defienden el no encarcelamiento de traficantes o usuarios no puede creer en eso simplemente por ser en contra de las cárceles.

Eso me preocupa porque está más allá de los problemas que tenemos con los más conservadores de las más distintas clases sociales. Se lo digo porque madres y padres que perdieron hijos en razón del vicio con las drogas o porque trabajaban para el tráfico, o mismo madres que perdieron sus hijos para la violencia generada y no porque estuviesen involucrados con drogas, claman por el fin del uso y venta de drogas. Estas personas muchas veces dicen: «iOdiamos las drogas! iQueremos el fin de las drogas!», «Nosotros vivimos en comunidades en que la policía invade y mata a inocentes debido a las drogas», «iMi hijo era dependiente de drogas y murió por el consumo de drogas!». Y esta me parece una cuestión bastante sensible. La guerra contra las drogas mata un número muy grande de personas inocentes y parece difícil explicar para los que perdieron seres queridos que las drogas pueden ser usadas y comercializadas legalmente y de manera recreativa.

\section{Sebastian Scheerer:}

Sí, eso es una cuestión muy compleja porque las drogas son como el alcohol. Son substancias arriesgadas para la recreación. Eso también es una verdad para los cigarrillos, para el aguardiente, para el vino, cerveza... Obvio que de maneras distintas, pero es verdad de que son substancias problemáticas las drogas, tanto legales cuanto ilegales. Y eso hace la cuestión muy difícil, hasta porque muchas veces las drogas sí matan a las personas. El uso de las drogas puede matar, el alcohol, el tabaco, las drogas ilícitas, todas matan a mucha gente. Entonces, eso es verdad, todos lo sabemos. Y no me opongo a las familias que dicen: «En nuestra familia nadie va a usar drogas, nosotros no toleramos ese tipo de comportamiento». $Y$ entiendo los padres que dicen a sus hijos: «No salgan con chicos que los padres consumen drogas». Eso es completamente viable y puede ser bueno para estas personas.

Al mismo tiempo es muy difícil decir: «La legislación sobre las drogas es insatisfactoria Y debería ser disuelta y las drogas legalizadas». Puede parecer una contradicción, pero en realidad no lo es porque una mala legislación de drogas crea muchos más peligros para personas que usan drogas de manera recreacional. Cuando se tiene una mala ley sobre drogas, entonces se tendrá un ataque a las drogas donde se podrá ser herido por tiros y muerto, por estar cerca a alguien con drogas. Sus hijos (as) pueden experimentar drogas y ellos pueden entrar en una fase en que consumen, aunque usted sea contra el uso de drogas. Ellos pueden ser parados por la policía y pueden ir para la cárcel y dentro de esta pueden morir, eso sucede... Y todas estas personas podrían estar vivas si las drogas no fueran prohibidas. Podría ser considerado que el uso de drogas cuando adolescente es una fase, como es el caso del vino y el aguardiente, son fases para todos los adolescentes. Apenas hay adolescentes que 
consumen drogas legales y ellos tienen mayores chances de sobrevivir que los que consumen drogas ilegales. Podemos considerar que ellos viven en esta fase y después la van a superar y se convertirán en ciudadanos comunes. Así ellos no tendrán riesgos de ir para una institución de menores, o mismo para cárceles y después presos pudiendo hasta mismo morir en estas. Estas personas pueden morir en la cárcel, o por policías etc.

¿Entonces porque no tratamos las drogas ilegales como tratamos las legales? Podemos ser contra ellas, podemos hablar para nuestros hijos que no usen, pero si ellos experimentan, ellos no deberían ir para prisiones. Mis hijos no fueron para prisiones por tomaren alcohol, mismo que yo les tenga dicho para no hacerlo. iMe quedo feliz que no hayan ido preso! Mi padre no fue a la cárcel porque fuma tabaco, y me quedo feliz por él también. Él podría haber sido muerto dentro de una penitenciaria si el cigarrillo fuera ilegal y una vez allá, podría haber sido muerto. Y si hubiera muerto yo ni siquiera existiría, y eso sería muy triste para mí, risas.

Entonces es tan lógico que la criminalización de las drogas es un riesgo adicional para los riesgos de las drogas mismas. Hoy muchas personas más mueren por este riesgo adicional de la prohibición de las drogas y de la guerra a las drogas, que mueren por el consumo de estupefacientes. Probablemente en Brasil, hasta el mes de junio del 2018, nadie se murió este año por haber fumado marihuana. Pero muchas personas que manejan la marihuana, que trabajan con la marihuana, probablemente muchas de ellas murieron por la guerra a las drogas. Entonces, muchas más personas que tienen una conexión con la marihuana mueren por la prohibición de las drogas que por el consumo. ¿Cómo podemos hacer una ley que más hace mal para la sociedad que el propio objeto que la ley va en contra? iEso no es racional! Y lo mismo sucede con las otras drogas ilícitas.

En Portugal tienen una Ley de Drogas desde el 2001 que descriminaliza todas las drogas, al menos para el consumo. Si es traficante seguirán llevando a la prisión, pero si está probado que es consumidor, no importa qué tipo de droga que tenga, ellos nunca le van a prender. Mismo que le encuentre 20 veces con drogas, mismo que sea opio, no irá para la cárcel por consumo de drogas. Ellos pueden recomendar que busque tratamiento, psicólogos, grupos de narcóticos, pero no le enviarán para la cárcel. Y parece algo sencillo que es fantástico porque funciona. Las personas están más felices en Portugal porque piensan que las cosas están más fáciles que en territorios de países que prohíben las drogas. Porque en estos lugares la droga es una tensión y un peligro. Reafirmando que este peligro no viene de la droga, pero viene de la prohibición de esta.

Entonces, apoyo a todos que dicen que no les gusta las drogas, que no quieren probarlas y ni desean que sus familiares tengan contacto con estas. Pero quiero que las drogas ilegales sean tratadas legalmente como tratamos el tabaco y el alcohol. Y soy en contra de las prohibiciones del alcohol que nunca ha funcionado, no va a funcionar y crea una serie de problemas extras. También soy contra la prohibición de cigarrillos. Pero soy a favor de todas las restricciones que dicen para las personas no fumaren en shopping centers, en restaurantes, en el trabajo. - - Eso está muy bueno, pero nosotros no debemos prohibir los cigarrillos, aunque mismo maten a las personas. Hasta porque si prohibimos a los cigarrillos vamos a crear el mismo problema que tenemos con las drogas ilegales, donde generamos muchas más personas muertas que si estas apenas fumaran. Y hoy en día tenemos muy buenos artículos científicos, escritos por investigadores serios, que nos llaman la atención para que si se aplica la prohibición de los cigarrillos esto traerá los mismos problemas que enfrentamos con la 
guerra a las drogas, solo que muy potenciado.

Así que soy fan del modo como Uruguay trató la cuestión de las drogas. En Uruguay la Ley de las Drogas más progresista está prevista apenas para el cannabis, pero allá de hecho han legalizado el cannabis, o sea, no hay riesgo de un policía incriminar un usuario o prenderlo, no hay riesgo de exclusión social por el uso, y esa es la manera como deberíamos lidiar con la cuestión de las drogas. Y es como podríamos lidiar con todas las drogas, no apenas la marihuana.

\section{Entrevistadoras:}

Bueno, esta pregunta se refiere más a su última clase en la USP. Durante su ponencia usted ha enumerado 8 tipos de asesinatos: aborto, genocidio, suicidio, guerras, sanciones, legítima defensa, eutanasia y homicidio. Mientras hablaba de eso yo pensaba que ustedes en Europa enfrentan hoy el grande problema de refugiados. Es posible percibir que no es una muerte directa porque no los asesinan, pero los dejan que mueran. Acá en Brasil tenemos un grande problema también que son las personas muy pobres, abajo de la línea de miseria que mueren por el hambre, no tienen acceso a la salud, educación etc. Entonces me quedo preguntando si esos crímenes de Estado no pueden ser considerados como asesinatos. Porque me quedo pensando que no son muertes directas entre personas, pero es el descaso de los Estados que termina por asesinarlas.

\section{Sebastian Scheerer:}

Ese una muy buena pregunta. La diferencia entre asesinato directo en que se promueve la muerte y el otro caso es dejar que muera el sujeto. En la ley ellos comúnmente distinguen eso entre matar activamente una persona o dejar que una persona muera. La idea básica es que cuando se mata directamente una persona es entendido como homicidio, moralmente y legalmente reprensible. Ahora cuando se deja morir a una persona legalmente no hay culpado por un crimen, porque nadie hizo nada. Así que, dejar a alguien que muera es moralmente difícil, pero legalmente está ok.

Existen obvio, excepciones, como cuando es el padre de un niño que está por morir, y no lo puede dejar morir que esto se entiende como homicidio porque no hizo nada. Es una perversidad que no es permitida por la posición de alguien que tiene que cuidar a ese niño, tiene la obligación de cuidar a esa persona. Y si no la cuida, entonces la ley le tratará como responsable por haber dejado que muera y puede ser valorado con un acto activo.

En la filosofía hay un caso muy peculiar llamado El dilema del tranvía (The Trolley case). En este caso hay un tren que no tiene ningún conductor en el tranvía, y el tren está bajando para cerca de 3 personas que están en las vías. Y estas personas no pueden oírlo porque están trabajando, y no saben que el tren se encuentra sin conductor, bajando derecho, y va al encuentro de ellos. Y usted está cerca de estas vías y ve lo que está pasando. Y ve que hay una intersección en que la vía puede caer para la derecha o seguir derecho. Y puede cambiar la dirección del tren tirando una palanca, lo que haría con que el tren fuera para la derecha. Está cerca de la palanca y es fácil de hacerlo. Entonces, claramente lo haría, es fácil responder a esa cuestión. Pero entonces ve que en la vía de la derecha hay una persona en las vías del tren. ¿Entonces que haría? ¿Cambiaría la dirección del tren? Y este es el The Trolley Case. Entonces el dilema es: Va a hacer algo para salvar a las tres personas, pero va a elegir que se muera una persona en las vías de la derecha. Usted no sería exactamente quien ha matado a esta persona, pero habrá tirado la palanca que ha ocasionado la 
muerte de ella. Pero la buena noticia si lo elige es que apenas matará a una persona. Cuando no hace nada las tres personas se van a morir, pero no siendo el padre de ellas, no tiene ninguna obligación legal con ellas para salvarlas. Puede apenas dejar que suceda lo que ya estaba sucediendo, que es el tren bajar las vías en dirección a ellas.

Y es una cuestión muy interesante pensar lo que haría, o que se debería hacer. La mayoría de los hombres contestan que cambiarían la dirección del tren y salvarían a las tres personas, en lugar de una única persona. Hice este experimento con personas y, en cambio, la mayoría de las mujeres dicen que no cambiarían el curso del tren, porque el destino podría cambiar siempre de manera imprevisible. A veces el tren podría descarrilar antes de bajar hacia las tres personas, lo que no es parte del problema, pero algunos intentan inventar mecanismos para lidiar con una elección. $Y$ muchas dicen: «Bueno, yo no soy madre de estas personas, yo no tengo que elegir quien va a morir. Es trágico lo que sucederá, pero yo no quiero sentirme responsable por la muerte de una persona, porque cuando cambio el rumbo del tren yo decido quien muere. Si intervengo me siento culpable".

Así que es una pregunta muy compleja de responder. Y queda todavía más compleja cuando usted no está cerca de la palanca que puede cambiar el rumbo, pero sí, está en el puente, antes de la bifurcación de las vías, más lejos de la palanca. En el puente va a ver todo lo que va a ocurrir, pero no tiene la palanca para cambiar el rumbo del tren. Sin embargo, detrás usted hay un hombre muy gordo y sería fácil apenas empujarlo y él bloquearía que el tren fuera para cualquier de uno de los dos lugares.

En este caso, la mayoría de las personas que dicen que cambiarían la palanca no son capaces de decir que empujarían al hombre gordo a las vías. Aunque salga lo mismo, estaría sacrificando a una persona en detrimento de otras. Pero lo más interesante de todo eso, y ahora llegamos en la pregunta de lo «dejar la persona morir». De alguna manera, la mayoría de las personas no empujarían al hombre gordo, porque existirían instintos morales de que es un asesinato empujar a alguien de un puente para impedir que el tren baje y mate tres personas. $Y$ las personas no quieren cometer un asesinato, mismo que el asesinato genere efectos positivos. Es algo moralmente distinto de cometer un asesinato para hacer algo bueno o dejar que alguien muera para hacer una cosa buena.

No hacer nada no es malo por sí, pero matar una persona sí es muy malo por sí. Entonces puede dejar a las personas que mueran en el Mediterráneo, eso es malo, y es triste también. Y puede preguntar «¿Cómo he sido capaz de eso?» Pero el sujeto no es el padre de esas personas, usted no está matando a estas personas directamente, está dejando que mueran de hambre o en el Mediterráneo. Pero es distinto de ahogar a la persona personalmente en el Mediterráneo. Eso en la filosofía occidental lo puede encontrar en la religión, lo puede encontrar en Thomas de Aquino, él también ha pensado sobre eso, de otra forma obvio, pero elucubraba sobre eso. Y lo que Tomás de Aquino hablaba es que nunca se podrá elegir por cometer el acto malo en su propria vida por ninguna razón. Pero, por otro lado, no tomar partido y permitir que las cosas ocurran, se puede hablar respecto a eso.

Creo que esa línea de pensamiento nos sigue hasta hoy. Creo que es una pregunta de responsabilidad política y estoy seguro que los políticos alemanes no creen que es responsabilidad política de ellos. Ellos incluso prohibieron que se exportasen buenas embarcaciones para Libia, porque creen que cuando mejoren los barcos más personas vendrán como refugiadas. Así que estas personas tendrían que tener barcos precarios, que son más peligrosos. Eso es terrible. 
Por eso para contestar su pregunta, tratase de una pregunta de responsabilidad política. Pero yo no pondría en la misma lista de muertes activas, o sea, de personas matando a personas. Eso son personas dejando que otras personas mueran, y eso es un tema distinto. Obvio que es un asunto muy importante, muy emocional y complejo de manera filosófica, pero en este momento yo te contestaría que hay una gran diferencia.

\section{Entrevistadoras:}

Por fin, me gustaría preguntar sobre lo que usted dijo estar investigando ahora. Hoy en la USP nos ha contado que tiene esta nueva teoría sobre dos ciclos llenos (two full cicles). ¿Podría explicarnos sobre eso un poco más detalladamente?

\section{Sebastian Scheerer:}

Sí, claro. Nos acostumbramos a creer que la historia de los encarcelamientos es una historia de progresos. Había las casas de corrección que confinaban personas de manera indiscriminada, donde las personas se quedaban en cuarentenas solitarias por mucho tiempo, antes de las celdas. Cuando estas surgieron eran limpias, muy buenas, donde las personas realmente buscaban rehabilitar otras personas, entonces tenían buenas intenciones y hasta mismo se gastaba mucho dinero en estos establecimientos. Esto sería un progreso. Y después tendrían aún más progresos cuando empezasen con las terapias dentro de las prisiones, con prisiones abiertas etc. Por eso, la idea de los penalistas era de que, si vivíamos en una época de progresos, entonces podríamos demostrarlo a través de la manutención con maestría de las prisiones.

Yo creo que la idea de progreso ya está equivocada de antemano. Lo que sucede realmente es que siguen con las prisiones de personas de manera indiscriminada con la actualización para confinamientos en solitarias, por ejemplo. Hoy podemos ver que el dicho progreso no es linear, sino circular. Y hoy en día estamos volviendo para el confinamiento en solitarias, después de todas las «aperturas» de la prisión, estamos volviendo para este escenario de confinamiento solitario. $Y$ así podemos percibir como muchos otros prisioneros están siendo dirigidos para las solitarias en los últimos diez años del siglo XXI mientras esto era una práctica común en el siglo XVIII, como nos muestra el trabajo de John Howard, escrito en 1777. John Howard hizo un enorme trabajo empírico sobre las cárceles en que relataba exactamente como esas prácticas eran nocivas y esto volvió para el escenario actual. Todo lo que John Howard ha descrito en sus manuscritos sobre la falta de higiene, corrupción, deterioro, son escenarios exactamente iguales a los que vemos hoy en las cárceles.

Entonces, el progreso puede parecer como un progreso porque miramos para la situación degradante en que se encuentran las prisiones hoy, pero no es un progreso del punto de vista histórico. Es un proceso que gira en círculos. iEso es una buena señal de como todo este sistema debe acabar de una vez!

\section{Entrevistadoras:}

Sí. Muy bien Sebastian, yo te agradezco muchísimo por la entrevista. Ha sido muy aclarador charlar con usted sobre el abolicionismo y sobre el escenario del hiperencarcelamiento que enfrentamos hoy. iMuchas gracias!

\section{Sebastian Scheerer:}

iNo hay de que! Yo me alegro en poder contribuir con usted y con su investigación. 
(Recebido para publicação em agosto de 2020)

(Reapresentado em setembro de 2020)

(Aprovado para publicação em setembro de 2020)

\section{Cite esta entrevista}

SCHEERER, Sebastian. Entrevista conduzida por Tamires Alves e Gabriela Gusis. Tradução: Jasmin Sánchez. Revista Estudos Políticos: a publicação semestral do Laboratório de Estudos Hum(e)anos (UFF).Rio de Janeiro, Vol.11 |N.1, pp. 3-15, outubro de 2020. 